\title{
UJI EKSPERIMENTAL PENGARUH TEMPERATUR LINGKUNGAN TERHADAP KINERJA MESIN PENDINGIN REFRIGERAN HIDROKARBON
}

\author{
M. Edi Pujianto*, Muhammad Subri, Muh. Amin, Purnomo \\ Jurusan Teknik Mesin, Fakultas Teknik, Universitas Muhammadiyah Semarang \\ Jl. Kasipah No.12 Semarang,50254. \\ *Email: vanhebleedi@gmail.com
}

\begin{abstract}
Refrigeran sintetik saat ini masih banyak digunakan untuk fluida kerja mesin pendingin. Pemanasan global merupakan salah satu dampak negatif dari penggunaan refrigeran sintetik. Salah satu alternatif yang dilakukan untuk menanggulangi hal tersebut adalah dengan menggunakan refrigeran alami. Sebagai contoh penggunaan hidrokarbon, propana dan isobutane sebagai pengganti CFC-12, sedangkan pengganti HCFC 22 adalah jenis propana. Penelitian ini bertujuan untuk mengetahui kinerja pengaruh penggantian refrigeran sintetis dengan refrigeran alami, metode yang digunakan yaitu melalui percobaan secara eksperimental pada sebuah air conditioner $(A C)$ dengan cara, mengganti refrigeran $R 22$ dengan $R$ 290. Selain itu, variabel lain yang digunakan dalam penelitian ini adalah temperatur dan kelembapan udara lingkungan. Temperatur udara lingkungan diatur pada keadaan $28^{\circ}, 30^{\circ} \mathrm{C}$, dan $38^{\circ} \mathrm{C}$. Dari hasil penelitian didapatkan coefficient of performance (COP) akan semakin turun seiring dengan peningkatan temperatur lingkungan.
\end{abstract}

Kata kunci: COP, R22, R290, Temperatur lingkungan.

\section{PENDAHULUAN}

Mesin pendingin siklus kompresi uap merupakan jenis mesin pendingin yang paling banyak digunakan saat ini, umumnya media yang digunakan sebagai fluida kerja yang memindahkan panas dari produk yang didinginkan ke lingkungannya adalah refrigeran sintetik. Sejak ditemukan sekitar tahun 1930 hingga pertengahan 1970, dampak penggunaan refrigeran sintetik seperti refrigeran Chloro Fluoro Carbon (CFC), dan Hydro Chloro Fluoro Carbon (HCFC) belum menjadikan masalah lingkungan. Hal ini bukan berarti penggunaan refrigeran tersebut tidak memiliki dampak negatif terhadap lingkungan, tetapi lebih disebabkan terbatasnya pengetahuan dan kesadaran lingkungan pada saat itu. Dengan bertambahnya pengetahuan dan kesadaran lingkungan, ternyata penggunaan refrigeran sintetik tersebut menimbulkan masalah terhadap lingkungan, refrigeran yang semula dipandang sangat ideal dan sempurna, kini dipandang berbahaya sehingga perlu dihapus penggunaannya (Powell, 2002).

Hal ini kemudian mendorong negaranegara di dunia termasuk Indonesia untuk kemudian bersama-sama melakukan pencegahan dan perbaikan dengan membuat kesepakatan. Kemudian kesepakatan ini dikenal dengan konvensi Wina pada tahun 1985 diikuti dengan kesepakatan Montreal tahun 1987. Guna mengurangi dampak ODS (Ozone Depleting Substance) tersebut, pada tahun 1992 Indonesia telah menandatangani protokol Montreal. Pada saat itu pula Indonesia telah mencanangkan program "Indonesian Country for The Phase Out of Ozone Depleting Substance (ODS) under The Montreal Protokol". Sehingga mulai awal tahun 2020 sampai dengan tahun 2030 bahan pendingin refrigeran jenis HCFC akan dihapus dan dihentikan penggunaannya.

Alternatif yang dilakukan oleh para peneliti untuk menanggulangi hal tersebut, salah satunya adalah penggunaan refrigeran hidrokarbon campuran propana dan isobutane sebagai pengganti CFC-12, sedangkan pengganti HCFC 22 adalah propana atau R 290. Sebenarnya pemakaian hidrokarbon sebagai refrigeran sudah dikenal masyarakat sejak 1920 di awal teknologi refrigerasi mulai dikembangkan bersama fluida kerja natural lainnya seperti amonia, dan karbon dioksida (Calm \& Hourahan, 2001) Sejak ditemukan pada tahun 1930 refrigeran CFC (Chloro-Fluoro-Carbon) dan HCFC memegang peranan penting dalam sistem refrigerasi dan mengondisikan udara. Hal ini dikarenakan refrigeran tersebut memiliki properti fisika dan termal yang baik, stabil, tidak mudah terbakar, tidak beracun dan kompatibel terhadap sebagian 
besar bahan komponen dalam sistem refrigerasi (Powell, 2002).

Seperti yang telah dijelaskan sejak awal bahwa pada sistem pendingin kompresi uap refrigeran merupakan media untuk memindahkan kalor. Refrigeran ini memegang peranan sangat penting dan sampai saat ini masih banyak digunakan pada berbagai mesin refrigerasi, salah satunya adalah HCFC 22 atau umumnya refrigeran sintetis. Refrigeran ini mempunyai nilai ODP (Ozone Depleting potensial) dan GWP (global Warming potential) yang cukup tinggi. ODP merupakan ukuran relatif tingkat perusakan ozon suatu bahan terhadap tingkat perusakan ozon oleh R-11. Sebagian besar negara mengurangi emisi dari pembangkit listrik sehingga mengurangi dampak emisi terkait produksi energi tidak langsung.

Tabel 1. Data potensi pemanasan global refrigeran (Tanaka dkk., 2018)

\begin{tabular}{ccc}
\hline Refrigerant & ODP & GWP \\
\hline CFC-11 & 1 & 4600 \\
CFC-12 & 0.82 & 10.60 \\
HCFC-22 & 0.034 & 1700 \\
HCFC-123 & 0.012 & 120 \\
HFC-134a & 0 & 1300 \\
HFC-152a & 0 & 120 \\
R-407C & 0 & 1700 \\
R-410A & 0 & 2000 \\
HC-290 & 0 & $\sim 20$ \\
HC-600a & 0 & $\sim 20$ \\
Ammonia (R-717) & 0 & $<1$ \\
Water (R-718) & 0 & $<1$ \\
Carbon dioxide & 0 & 1 \\
(R-744) & & \\
\hline
\end{tabular}

Nilai ODP dan GWP beberapa refrigeran dapat dilihat pada Tabel 1. Salah satu alternatif refrigeran pengganti terhadap refrigeran sintetis HCFC 22 adalah refrigeran hidrokarbon jenis propana (HC 290), karena memiliki nilai ODP 0 dan GWP relatif kecil. Penelitian tentang refrigeran hidrokarbon sebagai bahan ramah lingkungan telah dimulai cukup lama dan terus dikembangkan untuk memperoleh hasil yang paling optimum.

Faktor pengaruh udara lingkungan terhadap Coefficient Of Performance (COP) mesin pendingin menggunakan refrigeran R22 dengan R290. Faktor pengaruh udara lingkungan terhadap konsumsi energi listrik pada sistem pendingin menggunakan refrigeran R22 dan R290.
Tujuan penelitian ini adalah untuk mengetahui kinerja sistem pendingin dengan menggunakan refrigeran R22 dan R290 terhadap pembebanan temperatur lingkungan serta konsumsi energi listrik yang terjadi akibat suhu udara lingkungan

\section{METODE PENELITIAN}

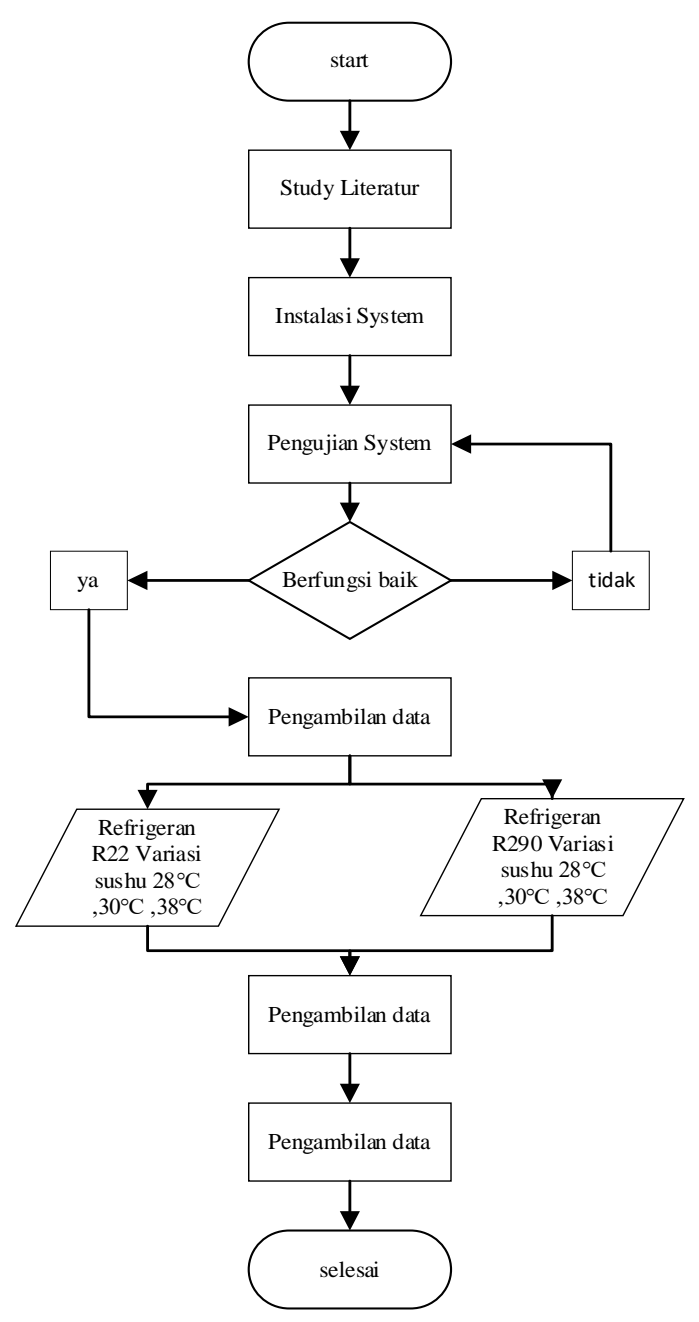

\section{Gambar 1. Diagram Alir Penelitian}

Pengujian dilakukan menggunakan satu sistem yang sama. Urutan penelitian seperti pada gambar 1. Pengamatan dilakukan terhadap parameter yang diukur yang kemudian dianalisis untuk mengetahui kinerja sistem Parameter yang diukur meliputi tekanan dan temperature kondensor, evaporator, kabin, temperatur lingkungan, dan temperatur produk. Tegangan, arus dan kwh pada motor kompresor. Refrigeran R22 dan R290 sebagai fluida kerja sistem. Data keadaan system diambil menggunakan Instrumentasi kemudian dilakukan pengolahan data menggunakan software Refprop. 


\section{HASIL DAN PEMBAHASAN}

Proses pengerjaan yang sama seperti contoh kasus dari data pengamatan dengan sistem menggunakan refrigerant R22 dan R290, nilai entalpi untuk sistem yang memakai variasi udara yang masuk sebagai pembebanan ditunjukkan pada Tabel 2.

Tabel 2. Hasil Perhitungan Entalphy

\begin{tabular}{lcccc}
\hline \multirow{2}{*}{ Refrigerant } & $\mathbf{h 1}$ & $\mathbf{h} 2$ & $\mathbf{h 3}$ & $\mathbf{h 4}$ \\
& $\mathrm{kJ} / \mathrm{kg}$ & $\mathrm{kJ} / \mathrm{kg}$ & $\mathrm{kJ} / \mathrm{kg}$ & $\mathrm{kJ} / \mathrm{kg}$ \\
\hline $\mathrm{R} 2228^{\circ} \mathrm{C}$ & 416.872 & 466.22 & 238.099 & 238.099 \\
$\mathrm{R} 2230^{\circ} \mathrm{C}$ & 417.642 & 467.749 & 240.338 & 240.338 \\
$\mathrm{R} 2238^{\circ} \mathrm{C}$ & 418.137 & 469.038 & 244.545 & 244.545 \\
$\mathrm{MC}-2228^{\circ} \mathrm{C}$ & 595.79 & 677.741 & 279.302 & 279.302 \\
$\mathrm{MC}-2230^{\circ} \mathrm{C}$ & 597.363 & 680.282 & 282.97 & 282.97 \\
MC-22 38 ${ }^{\circ} \mathrm{C}$ & 596.291 & 679.615 & 294.783 & 294.783 \\
\hline
\end{tabular}

Gambar 4 menunjukkan perbedaan entalphy yang sangat signifikan dari refrigeran R22 dan R290. Hal ini juga di pengaruhi oleh nilai flammability R290 yang cukup tinggi.

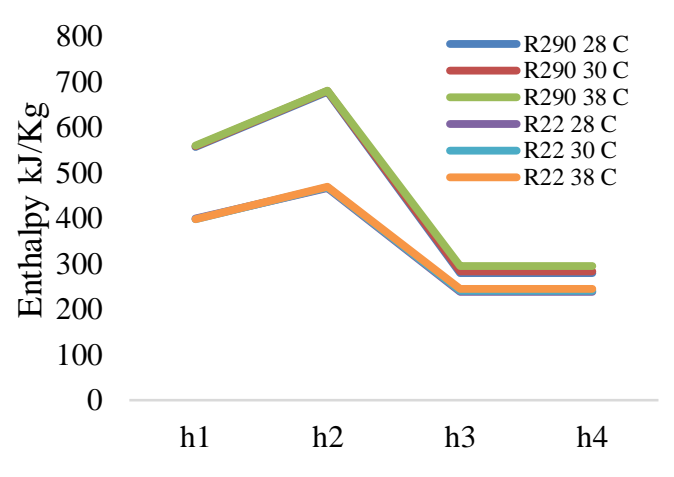

\section{Gambar 2. Grafik Entalphy}

Dari data Tabel.2 temperatur di atas di ambil untuk memvariasi temperatur udara yang di kondisikan di luar ruangan atau kondisi batas pada proses pengujian sistem pendingin kompresi uap, dengan hasil seperti yang di tunjukan Gambar 3 pengaruh variasi temperatur lingkungan terhadap kalor yang di serap pada evaporator.

Gambar 3 memperlihatkan bahwa efek refrigerasi dengan refrigeran HCFC 22 lebih kecil dibandingkan dengan yang menggunakan hidrokarbon pada berbagai variasi pengisian, hal itu terjadi sebagai akibat bahwa kalor laten hidrokarbon lebih besar dibandingkan dengan HCFC 22. Efek refrigerasi pengisian refrigeran R290 berbagai variasi temperatur yang masuk pada kondensor $28^{\circ} \mathrm{C}, \quad 30^{\circ} \mathrm{C}, \quad 38^{\circ} \mathrm{C}$ yaitu sebesar $276,989 \mathrm{~kJ} / \mathrm{kg} ; 275,21 \mathrm{~kJ} / \mathrm{kg} ; 264,957$ $\mathrm{kj} / \mathrm{kg}$. massa yang di masukan ke dalam sistem juga dapat mempengaruhi perubahan nilai efek refrigerasi . Perbedaan yang signifikan di pengaruhi sifat-sifat gas itu sendiri

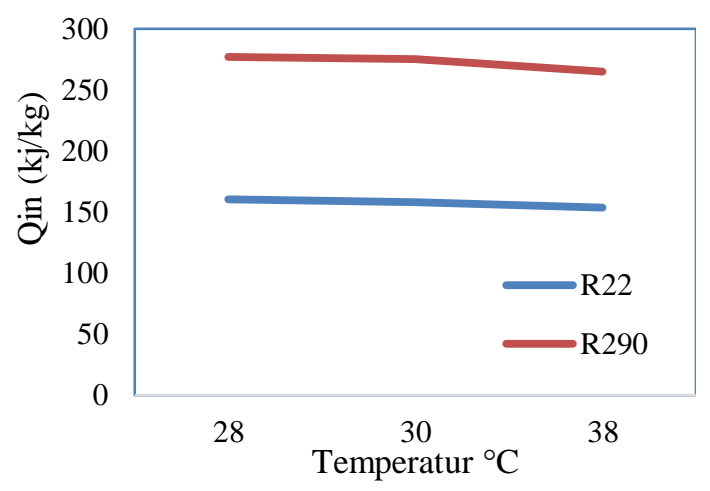

Gambar 3. Kalor yang diserap

Kalor yang di lepas pada kondensor menurun seperti yang di tunjukan pada Gambar 4, kejadian ini sebagai akibat naiknya laju aliran massa refrigeran, sehingga entalpi refrigeran masuk kompresor berkurang

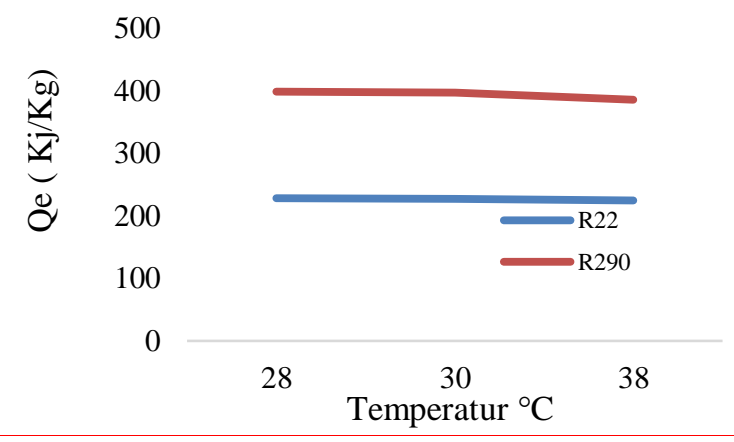

Gambar 4. Kalor yang di lepas

Refrigeran R22 berbagai variasi pembebanan pada kondensor $28^{\circ} \mathrm{C}, 30^{\circ} \mathrm{C}, 38^{\circ} \mathrm{C}$ yaitu $\quad 398,439 \quad \mathrm{~kJ} / \mathrm{kg}, \quad 396,63 \mathrm{~kJ} / \mathrm{kg}$, $385,517 \mathrm{~kJ} / \mathrm{kg}$. Refrigeran R290 berbagai variasi pembebanan pada kondensor $28^{\circ} \mathrm{C}, 30^{\circ} \mathrm{C}, 38^{\circ} \mathrm{C}$ yaitu $398,439 \mathrm{~kJ} / \mathrm{kg}, 396,63 \mathrm{~kJ} / \mathrm{kg}, 385,517 \mathrm{~kJ} / \mathrm{kg}$.

Salah satu parameter yang sering digunakan untuk mengetahui kinerja sistem refrigerasi kompresi uap adalah dari nilai COP, walaupun hal itu bukan segalanya karena faktor pencapaian temperatur ruangan yang juga harus mendapat perhatian karena hal ini menyangkut udara ruang yang didinginkan. Hasil perhitungan yang dibantu dengan perangkat coolpack kemudian digambarkan dalam bentuk grafik seperti terlihat pada Gambar 5 terlihat bahwa pencapaian nilai 
coefficient of performance tertinggi yaitu 3.86191 pada variasi temperature udara yang masuk pada kondensor $28^{\circ} \mathrm{C}$.

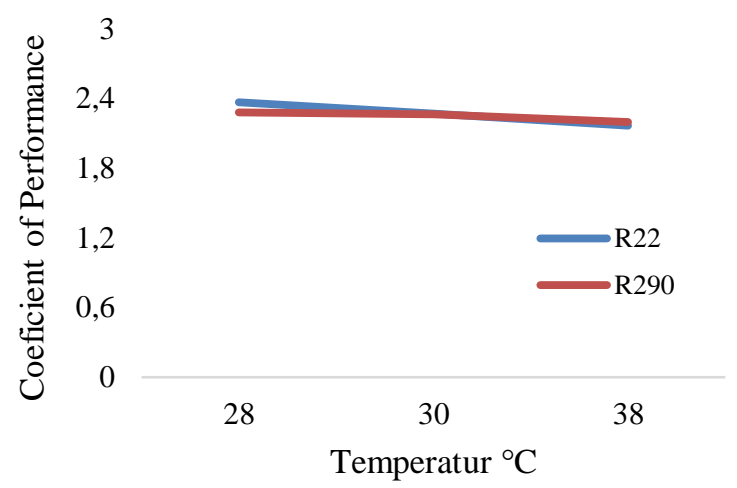

Gambar 5. Coefficient of Performance

Seperti yang di jelaskan (Pramudantoro, 2017) Nilai COP adalah nilai yang paling umum di gunakan untuk menunjukkan kinerja pada system refrigerasi. Secara umum dapat dikatakan bahwa semakin tinggi nilai COP, maka semakin efisien mesin refrigerasi tersebut.

\section{PENUTUP}

\section{Kesimpulan}

Semakin meningkat temperature lingkungan akan menurunkan nilai COP $4 \%$ dari kondisi awal. Nilai COP pada suhu $28^{\circ} \mathrm{C}$ sebesar 2.36, saat $30^{\circ} \mathrm{C}$ sebesar 2.26 dan $38^{\circ} \mathrm{C} 2.16$.

\section{DAFTAR PUSTAKA}

Calm, J. M., \& Hourahan, G. C. (2001). Refrigerant Data Summary. Engineered systems.

https://elibrary.ru/item.asp?id=4320825

Powell, R. L. (2002). CFC phase-out: Have we met the challenge? Journal of Fluorine Chemistry, 114(2), 237-250. https://doi.org/10.1016/S00221139(02)00030-1

Pramudantoro, T. P. (2017). Pengaruh Variasi Massa Pengisian R290 Sebagai Refrigeran Pengganti R22 Pada Kinerja Freezer. ReTII. https://journal.itny.ac.id/index.php/ReTII/ar ticle/view/652

Tanaka, I. R., Fajar, B., Utomo, T. S., \& Yohana, E. (2018). Experimental Study Performance R-22 AC Split Retrofitted With Propane. 02021, 1-6. 